\title{
Retinitis por citomegalovirus bilateral con reacción tipo Coats en paciente portador del VIH
}

\section{Bilateral cytomegalovirus retinitis with Coats-like presentation in an HIV patient}

\author{
Perla A. Kawakami-Campos* \\ Secretaria de Salud, Ciudad de México, México
}

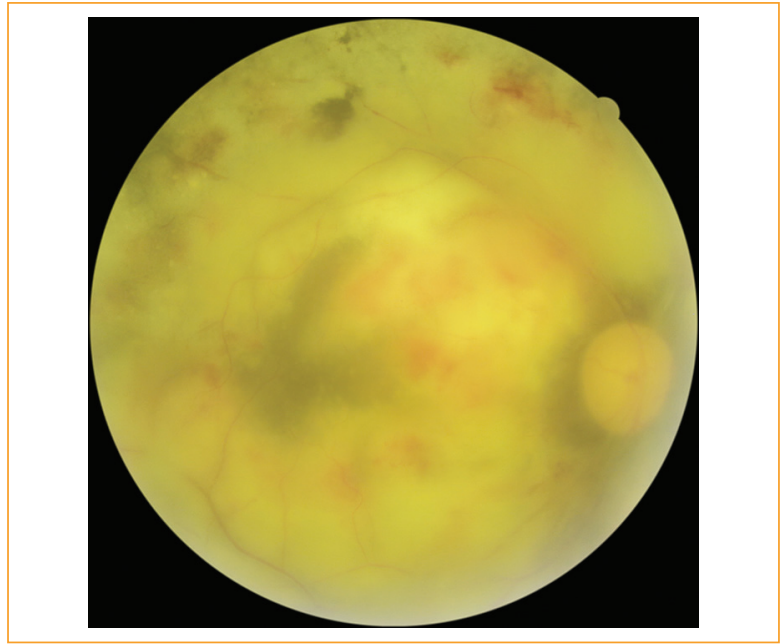

Figura 1. Imagen clínica del polo posterior del ojo derecho, visualización de calidad subóptima por vitritis densa. Se aprecian múltiples hemorragias en mancha asociadas a retinitis extensa, envainamiento vascular, exudados duros subretinianos coalescentes y palidez del nervio óptico.

Se trata de un paciente masculino de 43 años, valorado en la Clínica Especializada Condesa Iztapalapa por pérdida de $10 \mathrm{~kg}$ de peso no intencionada en 3 meses. Presenta cuadros múltiples de gastroenteritis con evolución tórpida a pesar del tratamiento y mala

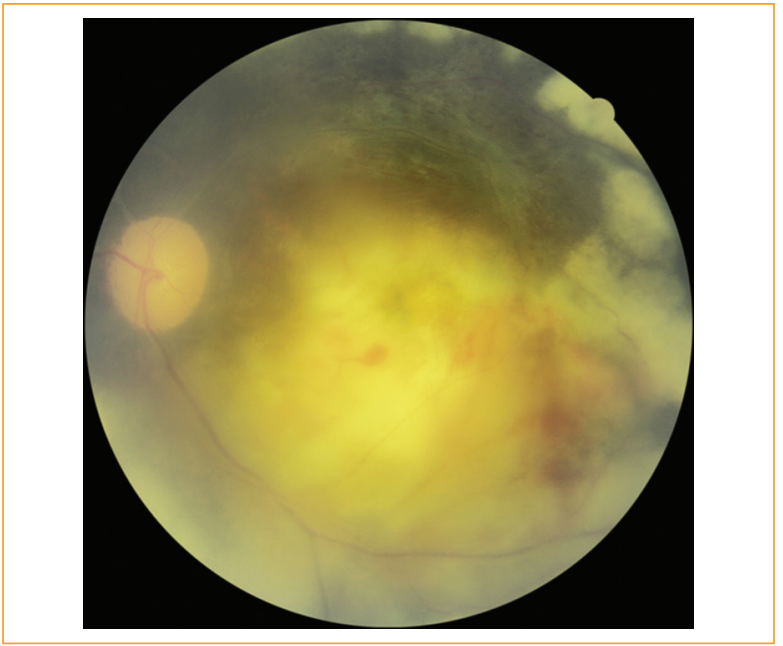

Figura 2. Imagen clínica del polo posterior del ojo izquierdo, visualización de calidad subóptima por vitritis densa. Observamos zonas de retinitis por citomegalovirus con hemorragias en mancha y flama asociadas, envainamiento vascular generalizado, palidez del nervio óptico y regiones de atrofia retiniana secundaria con fibrosis secundaria en la porción superior de la fotografía.

agudeza visual bilateral de 4 meses de evolución. Al momento del diagnóstico presenta conteo de linfocitos T CD4 de 19 cels $/ \mathrm{mm}^{3}$ con $3 \%$ y carga viral para VIH de $1,469,855$ copias/mililitro.

Correspondencia:

*Perla A. Kawakami-Campos

Combate de Celaya, $s / n$

Col. Vicente Guerrero, Del. Iztapalapa

Fecha de recepción: 29-07-2018 C.P. 09730, Ciudad de México, México Email: ayumika@gmail.com
Disponible en internet: 03-07-2019 Rev Mex Oftalmol. 2019;93(5):1-2

www.rmo.com.mx 0187-4519/๑ 2018 Sociedad Mexicana de Oftalmología. Publicado por Permanyer México. Este es un artículo Open Access bajo la licencia CC BY-NC-ND (http://creativecommons.org/licenses/by-nc-nd/4.0/). 


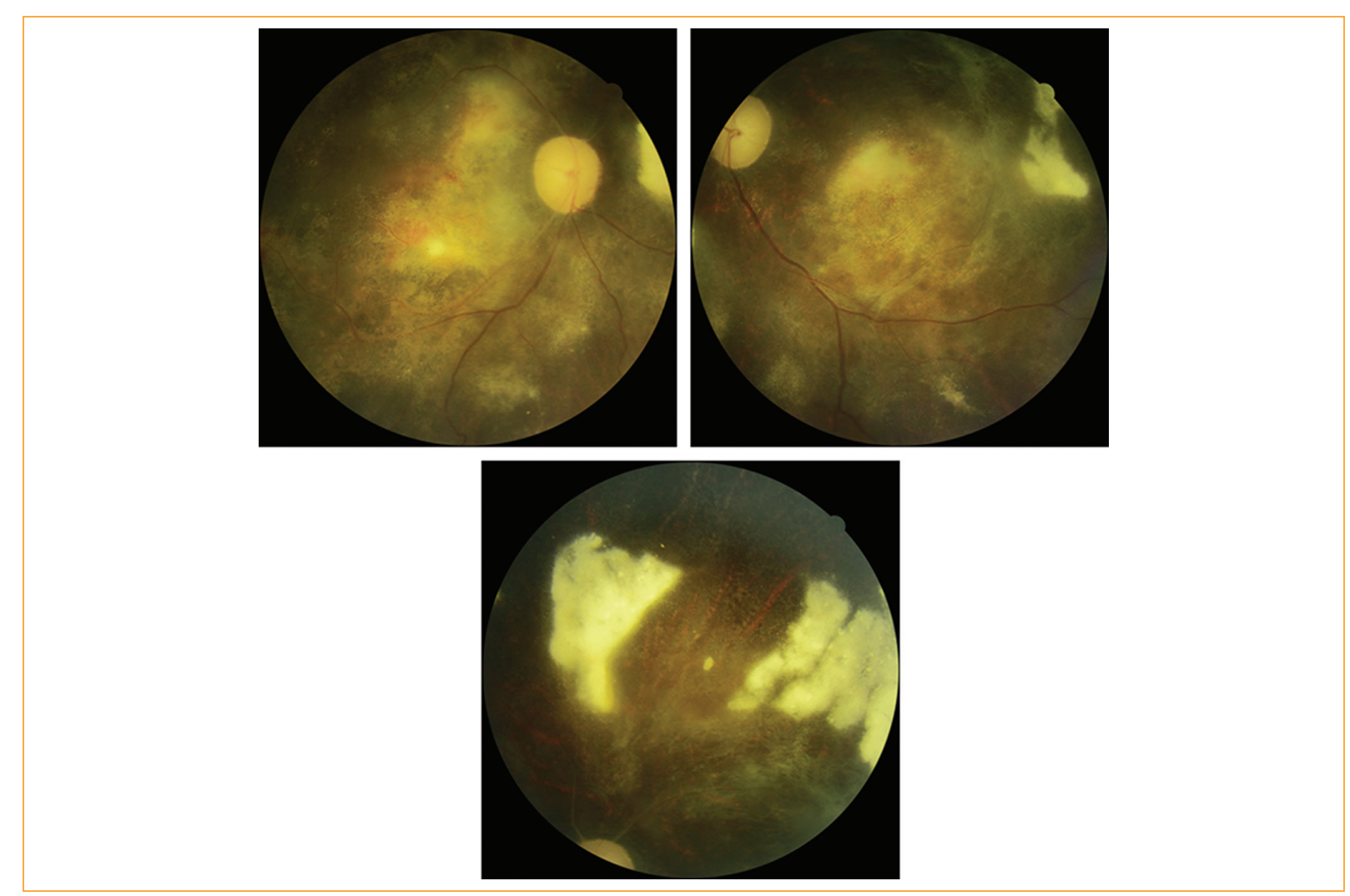

Figura 3. Fotografías clínicas del polo posterior de ambos ojos y la región peripapilar derecha, control fotográfico al mes de tratamiento. La resolución de la reacción exudativa evidencia atrofia retiniana extensa con visualización del epitelio pigmentario de retina, hialinización vascular residual, atrofia óptica y fibrosis subretiniana en parches.

Acude a revisión oftalmológica en la que se encuentra agudeza visual en no percepción de luz en ambos ojos, segmento anterior conservado, defecto pupilar aferente bilateral, vitritis importante, retinitis por citomegalovirus extensa, que abarca de la zona 1 a la 3 en todos los cuadrantes, asociada a exudados subretinianos iridescentes en patrón coatiforme, palidez del nervio óptico, hialinización vascular extensa, envainamiento sobre emergencia vascular en ambos ojos (Figs. 1 y 2). Esta presentación con exudación subretiniana extensa se considera atípica respecto a los tres patrones descritos en esta patología: granular, llamarada y rama congelada. Debido a la naturaleza del servicio y el equipo disponible, no fue posible realizar estudios fluorangiográficos o de tomografía de coherencia óptica a este paciente.

Se inicia tratamiento con valganciclovir $900 \mathrm{mg}$ cada 12 h vía oral y 5 días después se le asignan antirretrovirales: emtricitabina $200 \mathrm{mg} /$ efavirenz $600 \mathrm{mg} /$ tenofovir disoproxilo $300 \mathrm{mg}$ cada $24 \mathrm{~h}$. El inicio escalonado del tratamiento tiene como objetivo disminuir el riesgo de síndrome inflamatorio por reconstitución inmune.

A pesar de encontrarse en no percepción de luz, el tratamiento para retinitis por citomegalovirus se consi- evidenciable de una infección sistémica viral con el potencial de poner en riesgo la vida del paciente.

Un mes después persiste el defecto pupilar aferente y la agudeza visual en no percepción de luz en ambos ojos. La retinitis por citomegalovirus se encuentra en vía de remisión, con reabsorción parcial de los exudados duros subretinianos, atrofia óptica y retiniana extensa con visualización del epitelio pigmentario de retina (Fig. 3).

El paciente deja de acudir a los servicios de salud del Distrito Federal a las pocas semanas de la última revisión oftalmológica.

\section{Responsabilidades éticas}

Protección de personas y animales. Los autores declaran que para esta investigación no se han realizado experimentos en seres humanos ni en animales.

Confidencialidad de los datos. Los autores declaran que han seguido los protocolos de su centro de trabajo sobre la publicación de datos de pacientes.

Derecho a la privacidad y consentimiento informado. Los autores han obtenido el consentimiento informado de los pacientes y/o sujetos referidos en el artículo. Este documento obra en poder del autor de correspondencia. 